\title{
COMBUSTION MODEL FOR SPARK IGNITION ENGINES OPERATING ON GASOLINE-ETHANOL BLENDS
}

\author{
J. M. Mantilla, ABSTRACT \\ D. A. Garzón, \\ and C. H. Galeano \\ This article presents a phenomenological combustion model using turbulent \\ flame propagation theory developed by Keck and coworkers, 1974. The \\ model was adapted to work with gasoline-ethanol blends, following \\ correlations presented by Bayraktar,2005. New sub-models were \\ introduced for intake valve velocity and combustion efficiency. These allow \\ simulating the effect of compression ratio, spark timing and fuel change. \\ Results show good agreement with the ones in the original work as well as \\ Departamento de Ingeniería Mecánica \\ Kr. 30 \# 45-03 Edificio 453 Of. 401 \\ with experimental results in a Cooperative Fuels Research (CFR) engine. \\ Bogotá ,Colombia \\ jmmantillag@unal.edu.co \\ dagarzona@unal.edu.co \\ chgaleanou@unal.edu.co \\ Keywords: Internal combustion engine, ethanol, combustion, \\ phenomenological model.
}

\section{NOMENCLATURE}

$V, \quad$ volume

$\rho_{c y}, \quad$ in-cylinder density

$A$, cylinder area

$d x$, longitudinal differential of volume change.

$\partial Q_{R}$, heat release from fuel

$\partial W$, closed system work

$d U$, internal energy differential

$\partial Q_{L}$, heat transfer from burned zone to unburned zone, cylinder walls and piston crown

$\partial Q_{\text {vap }}$, fuel vaporization energy

$C_{h}, \quad$ convective heat transfer coefficient

$C_{r}, \quad$ radiative heat transfer coefficient

$T_{c y}, \quad$ in-cylinder temperature

$T_{c w}, \quad$ cylinder wall and piston crown temperature.

$A_{c w}$, cylinder wall combustion chamber and piston crown combined area

$C_{k}$, thermal conductivity

$\mathrm{Nu}$, Nusselt number

$d_{c y}$, cylinder bore

Re, Reynolds number

$R_{c y}, \quad$ in-cylinder gas constant

$L_{s t}, \quad$ stroke length

$N$, crankshaft angular velocity

$m_{\text {vap }}$, fuel vapor mass in a time iterval

$h_{\text {vap }}$, fuel's Latent heat of vaporization

$m_{\text {fat }}, \quad$ fuel mass trapped

$d t$, time differential

$A F R, \quad$ air to fuel ratio

$m_{t a}$, air mass trapped

$S E, \quad$ scavenging efficiency

$f$ residual mass fraction

$\lambda$, air-fuel equivalence ratio

$m_{t}, \quad$ in-cylinder total air mass

$d T, \quad$ temperature differential

\author{
$\eta_{c}, \quad$ combustion efficiency \\ $d m_{b} / d t$, burned mass rate \\ $L H V$, Lower Heating Value \\ $S_{L}, \quad$ laminar flame speed. \\ $u^{\prime}, \quad$ characteristic turbulent speed
}

\section{INTRODUCTION}

Biofuels, oxygenated fuel or reformulated fuels as are known, are blends of a base fossil fuel with some fuel with oxygen atoms in its chemical structure (MacLean and Lave, 2003). Ethanol is one of the most used in the world. It is obtained from sugar cane, corn and beet distillation (Bayraktar, 2005, Bastianoni and Marchetini, 1996). This hydrocarbon, the ethanol, has one hydroxide replacing one hydrogen atom, and must be $99.95 \%$ anhydrous in order to properly work within the engine as a fuel (Bastianoni an Marchetini, 1996, Hansen et al, 2005]. However, in Brazil, hydrated ethanol has been used as a fuel with good results (Kojima and Johnson 2005).

Gasoline-ethanol blends have been of interest since energy crisis in the 70's, caused by OPEC (Organization of the Petroleum Exporting Countries) oil embargo (Bastianoni and Marchetini, 1996). In countries like Brazil, mixtures of gasoline and ethanol from sugar cane were implemented since mid 70's (Hammond, 1977), as a way of agricultural industry enforcement and pollutant emissions decrease strategy. In United States and Canada use of gasoline-ethanol blends or pure ethanol has had a slow implementation. This is because ethanol production and commercialization requires projects with high investments and, in some cases, negative return rates (Bayraktar, 2005, MacLean and Lave, 2003). That is why the governments, through subsidy or tax reduction, must help in the purpose of biofuel 
accomplishment, together with a long term policy (McLean and Lave, 2003, Hansen et al, 2005).

Documented tests in (MacLean and Lave, 2003, Hsieh et al, 2002) showed that power and torque does not decrease when gasoline-ethanol fuels are used, in spite of the smaller Lower Heating Value (LHV) of it, in contrast to pure gasoline. In fact, an increase in fuel consumption is expected (Al-Hasan, 2003), as well as a raise in engine's thermal efficiency ( $\mathrm{Li}$ et al, 2005). Research Octane Number, heat of vaporization and autoignition temperature also augment with higher ethanol concentration in fuel (MacLean and Lave, 2003, Hsieh et al, 2002, Hansen et al, 2005, Yüksel and Yüksel, 2004). Reid Vapor Pressure is bigger for ethanol compared to gasoline, but in blends, their value is influenced by gasoline quality, i.e how much butane it has and what are the T50 and T90 distillation temperatures (Orbital, 2002).

Combustion in general is improved by gasolineethanol blend use as a fuel in engines, when comparing to gasoline fuel only. The best way to see this is to look at carbon monoxide (CO) and total hydrocarbon emissions (THC), which decrease, 10\% to $40 \%$ for $\mathrm{CO}$ (Orbital, 2002, Li et al, 2005, AlBaghdadi, 2000) and $5 \%$ to $20 \%$ for THC (Niven, 2005, Hammel-Smith et al, 2002, Morris and Brondum, 2000), as ethanol concentration in the fuel increase. Oppose to that are the trend for nitrogen oxides (NOx), increasing $1 \%$ to $18 \%$ (Schifter et al, 2001, Apace, 1998, Mayote et al, 1994), and aldehyde, increasing 5\% to $200 \%$ (Health, 2003, Durbin et al), emissions.

In Colombia, the change to gasoline-ethanol blends began in 2006 following entirely the Brazilian model (Higuera et al, 2007). The main difference between Colombian and Brazilian engines is that the latter is more adapted to biofuels, while in Colombia the average engine fueling technology is the carbureted one, because the engine's average age is 15 years (Ministerio, 2010). Also, Colombian gasoline and ethanol has different quality of the Brazilian fuels and its major cities are located at different altitudes, from 0 to 2650 meters above sea level. For those reasons, it is especially important to know the behavior of this blend in Colombia's engines through better understanding of combustion via mathematical modeling.

To simulate engine combustion, numerous techniques had been developed. Some of the most used are the ones which employ burned mass fraction (Ferguson, 1986), heat release (Blumberg et al, 1979), zero and one dimensional (one or two zone) models (Blair, 1999), and more complex procedures like multi-dimensional modeling (Heywood, 1988). All of these can simulate a specific combustion process, with greater depth and computer resources demand as physical dimensions increase within the model (Haworth, 2005).

The aim of this paper a phenomenological two zone engine model was developed, following turbulent flame propagation theory (Blizard and Keck, 1974) to calculate mass fraction burned in a moving spherical flame front. New sub-models for combustion efficiency and intake velocity are proposed in order to work with different compression ratios, spark timing and gasoline-ethanol blends.

The paper starts with closed cycle modeling, including constrains and sub-models for every equation to be solved. It continues computational model and next comparative validation results from the numerical model and experiment are presented. Finally, conclusions are depicted.

\section{CLOSED CYCLE MODELING}

Closed cycle begins when compression of in-cylinder gas starts and finish when exhaust valve opens. This process includes compression, combustion and expansion of a homogeneous mixture of fuel and air (Heywood, 1988).

The following assumptions need to be posted first, in order to present the model equations:

- Gas composition are known in the moment of valve closing (Ferguson, 1986).

- In-cylinder gas during compression, combustion and expansion is considered as ideal (Blair, 1999).

- Compression is isentropic (Blair, 1999).

- Constant mass during compression and combustion (Blair, 1999). Blow-by are not considered.

- Species conservation are handled with chemical equilibrium.

- A turbulent flame propagation model is used to calculate mass fraction burned (Blizard and Keck, 1974, Blumberg et al, 1979, Beretta et al, 1983).

- Heat transfer ocurs from the burned zone to unburned zone, engine walls and piston crown (Annand and Ha, 1963).

- Pressure gradient is null (Heywood, 1988).

- Flame geometry model represents the effects on one physical dimension plus time (Annand, 1970).

- Flame front shape could be predicted from a geometric model (Heywood, 1988).

Including these assumptions, Eq. (1) and Eq. (2) for mass and energy conservation are obtained.

Mass Equation:

$$
\left(\frac{\partial \rho_{c y}}{\partial t}\right) A d x=0
$$

Species conservation:

Chemical equilibrium for the following reaction is proposed:

$$
\left(1-X_{E}\right) C_{n} H_{m}+\left(X_{E}\right) C_{2} H_{5} O H+A^{*}\left(O_{2}+3.76 N_{2}\right) \rightarrow
$$




$$
\begin{array}{r}
B^{*} \mathrm{CO}_{2}+D^{*} \mathrm{H}_{2} \mathrm{O}+E^{*} \mathrm{~N}_{2}+\mathrm{F}^{*} \mathrm{O}_{2}+G^{*} \mathrm{CO}+\mathrm{H}^{*} \mathrm{H}_{2}+I^{*} H+J^{*} \mathrm{O} \\
+\mathrm{K}+\mathrm{OH}+L^{*} \mathrm{NO}
\end{array}
$$

In Eq. (2), superscript * indicates estequiometric coefficients and $X_{E}$ ethanol volume ratio whitin the mixture.

Energy Equation:

$$
\frac{\partial Q_{R}}{\partial t}-\frac{\partial W}{\partial t}=\frac{d U}{d t}+\frac{\partial Q_{L}}{\partial t}+\frac{\partial Q_{v a p}}{\partial t}
$$

This equation is used for compression, combustion and expansion processes within closed cycle (Blair, 1999). $\partial Q_{R}$ is removed for expansion and compression, plus fuel vaporization for expansion (Heywood, 1988). On the other hand, $\partial Q_{L}$ is computed using Annand's theory (Annand and Ha, 1963) :

$$
\partial Q_{L}=\left(C_{h}\left(T_{c y}-T_{c w}\right)+C_{r}\right) A_{c w} d t
$$

In Eq. (3), $C_{r}$ is negligible and $C_{h}$ is calculated using Eq.(4) (Annand and Ha, 1963):

$$
\begin{gathered}
C_{h}=\frac{C_{k} N u}{d_{c y}} \\
N u=a R e^{0.7}
\end{gathered}
$$

with $a=0.49$ (Blair, 1999).

Fuel mass vaporization energy is determined using Eq. (6):

$$
\partial Q_{v a p}=\dot{m}_{v a p} h_{v a p} d t
$$

where $m_{v a p}$ is computed employing Eq. (7) through Eq. (9) (Blair, 1999, Blumberg et al, 1979):

$$
\begin{gathered}
m_{\text {vap }}=m_{f a t} / d t \\
m_{f a t}=m_{t a} / A F R \\
m_{t a}=m_{t} / S E
\end{gathered}
$$

with $S E$ (scavenging efficiency) defined in Eq.(18).

Heat release from fuel is caculated with Eq. (10) (Blair, 1999):

$$
\frac{\partial Q_{R}}{\partial t}=\eta_{c} m_{f a t} L H V\left(\frac{d m_{b}}{d t}\right)
$$

Combustion efficiency is calculated from (Blair, 1999), and it is the product of different efficiencies: one related to the fuel used and the others to the air to fuel ratio and scavenging efficiency. The equation for this term is:

$$
\eta_{c}=C_{b u r n} \eta_{a f} \eta_{s e}
$$

where:

- $C_{\text {burn }}$ is a parameter that introduces a value to accounting for local velocity influence, incomplete flame travel, partial burning and flame decay. Usually, this is a value for model adjustment. Instead, in this work the following equation is proposed:

$$
C_{\text {burn }}=X_{E}\left(0.354+\left(0.7974+0.5 X_{E} / X_{E}\right)\right)
$$

As can be seen, $C_{b u r n}$ is strongely dependant on ethanol concentration in the fuel.

- $\eta_{a f}$ is combustion efficiency related to equivalence ratio, and is calculated with:

$$
\eta_{a f}=-1.6082+4.6509 \lambda-2.0746 \lambda^{2}
$$

- $\eta_{s e}$ is related with the scavenging efficiency throught:

$$
\eta_{s e}=1.0
$$

if $S E>0.9$, or

$$
\begin{array}{r}
\eta_{s e}=-12.558+70.1088 S E- \\
135.67 S E^{2}+114.77 S E^{3}-35.542 S E^{4}
\end{array}
$$

if equivalence ratio Eq. (17) is between 0.8 and 1.2 .

$$
\lambda=A F R_{\text {est }} / A F R_{\text {actual }}
$$

For Eq. (15) and Eq. (16), $S E$ is the scavenging efficiency, defined as:

$$
S E=1-f
$$

The expression $d m_{b} / d t$ in Eq. (11) is obtained from the turbulent flame propagation model (Blizard and Keck, 1974, Beretta et al, 1983), which is briefly explained next, detailed information is given in the cited references.

Flame penetration equation is modeled with:

$$
\frac{d m_{b}}{d t}=\rho_{u} A_{f f}\left(u^{\prime}+S_{L}\right)-\frac{d \mu^{*}}{d t}
$$

The first term in the righthand part of Eq. (19) stands for flame propagation. The next one is fuel mass that is burned into the "wrinkles" of the moving turbulent flame front. Mixture burning is only possible whitin this zone. 
In Eq. (19) where,

- $\mu^{*}$ is a parametric mass, which is the difference between fuel mass burned and entrained mass $\left(m_{e}\right)$. Entrainment mass is the mixture mass (air and fuel) inside the turbulent flame front "wrinkles" with characteristic length $l_{t}$.

- $\frac{d \mu^{*}}{d t}$ is the parametric mass rate, defined like:

$$
\frac{d \mu^{*}}{d t}=\rho_{u} A_{f f} u^{\prime}-\frac{\mu^{*}}{\tau_{b}}
$$

with:

$$
\begin{aligned}
\tau_{b} & =l_{t} / S_{L} \\
l_{t} & =0.8 L_{i v}\left(\rho_{i} / \rho_{u}\right)^{3 / 4}
\end{aligned}
$$

- $A_{f f}$ is the flame front area, whose calculation procedure is explain later.

Flame propagation is analyzed in two steps. The initial is flame penetration, described as a turbulent propagation to the unburned zone without heat transfer (Ferguson, 1986), due to an expanding flame front with laminar velocity $S_{L}$, and a movement of fresh mixture, with characteristic turbulent velocity $u$ ', to the burned zone. In next step heat release by combustion is decribed, equation (10) (Beretta et al, 1983).

Laminar flame speed is computed from correlations presented by Gülder (1984), and summarized by Bayraktar (2005):

$$
S_{L}=S_{L 0}\left(\frac{T_{u}}{T_{0}}\right)^{\alpha}\left(\frac{P}{P_{0}}\right)^{\beta}\left(1-C^{*} f\right)
$$

$$
S_{L 0}=Z * W * \phi^{n} * \exp \left(-\zeta(\phi-1.075)^{2}\right)
$$

where $P_{0}$ and $T_{0}$ are reference conditions for Pressure and Temperature, $C$ is a constant with value of 2.5 when residual mass fraction $(f)$ is between 0

\begin{tabular}{|c|c|c|c|c|c|c|c|}
\hline Fuel & $\mathbf{Z}$ & $\begin{array}{c}\mathbf{W} \\
{[\mathrm{m} / \mathbf{s}]}\end{array}$ & $\eta$ & $\zeta$ & $\alpha$ & \multicolumn{2}{|c|}{ B } \\
\hline & & & & & & $\phi<1$ & $\phi \geq 1$ \\
\hline $\mathrm{C}_{8} \mathrm{H}_{18}$ & 1 & 0.4658 & $0 . \overline{-}$ & 4.48 & 1.56 & \multicolumn{2}{|c|}{-0.22} \\
\hline $\mathrm{C}_{2} \mathrm{H}_{5} \mathrm{OH}$ & 1 & 0.4650 & 0.250 & 6.34 & 1.75 & $-0.17 / \sqrt{\phi}$ & $-0.17 \sqrt{\phi}$ \\
\hline $\begin{array}{c}\mathrm{C}_{8} \mathrm{H}_{18}+ \\
\mathrm{C}_{2} \mathrm{H}_{5} \mathrm{OH}\end{array}$ & $1+0.07 \mathrm{X}_{\mathrm{E}}^{0.35}$ & 0.4658 & $\begin{array}{c}- \\
0.3026 \\
\end{array}$ & 4.48 & $1.56+0.23 \mathrm{X}_{\mathrm{E}}^{0.46}$ & \multicolumn{2}{|c|}{$\mathrm{X}_{\mathrm{G}} \beta_{\mathrm{G}}+\mathrm{X}_{\mathrm{E}} \beta_{\mathrm{E}}$} \\
\hline
\end{tabular}
and 0.3. Other parameters are defined in

Table 1.

Table 1. Coefficients for laminar flame speed calculation. $P_{0}=1 \mathrm{bar}, T_{0}=300 \mathrm{~K} . X_{E}$ and $X_{G}$ are gasoline and ethanol molar fractions (Bayraktar, 2005).

On the other hand, the turbulent characteristic speed is calculated as (Beretta et al, 1983):

$$
u^{\prime}=0.08 U_{i} \sqrt{\rho_{u} / \rho_{i}}
$$

where:

- $U_{i}$ is the mean inlet gas velocity, modeled using Blizard and Keck (1974) expression, and including a new term to account for fuel, spark timing and compression ratio changes. The equation for $U_{i}$ is:

$$
U_{i}=\eta_{v}\left(A_{p} / A_{v}\right) N L_{s t}\left(\rho_{u} / \rho_{b}\right)^{2.99-m}
$$

with $m=3.00851-3.86568 E-2\left(S T\left(\rho_{u} / \rho_{b}\right)\right)$, where $S T$ represents spark timing in degree BTDC.

This model has four limiting situations, which are (Beretta et al, 1983): a) Incipient flame development: $u$ is zero, then $S_{b}=S_{L}$.

b) Quasi-stable phase: $d \mu / d t \approx 0, S_{b}=u+S_{L}$

c) Initial burning phase: $t>l_{t} / u^{\prime}, \quad t$ being simulation time, then $\frac{S_{b}}{S_{L}}=1+\frac{\rho_{b} u^{\prime} r_{f}}{3 \rho_{u} S_{L} l_{t}}$, with $r_{f}$ as flame front radius.

d) Final burning: $A_{f f} \approx 0$ then $\frac{m_{b}}{m_{b F}} \approx e^{-\left(t-t_{F}\right) / \tau_{b}}$, where subscript $F$ means conditions at the end of the flame propagation.

Flame geometric model

A flame model must be coupled into the main combustion model. This model gives important information to know the area of the moving flame in any time step. The model recognizes a burned zone volume $\left(V_{f}\right)$ which depends of geometric parameters of a moving spherical flame front with center in the spark plug (Blizard and Keck, 1974, Annand, 1970). 
An adittional variable is also defined, called de burned gas radius $\left(r_{b}\right)$. This is the spherical surface radius which contains all the combustion products computed from equilibrium.

Flame radius can be calculated using the following equation (Beretta et al, 1983):

$$
r=r_{b}+u^{\prime} \tau_{b}\left[1-e^{\left(-\left(r_{b} / u^{\prime} \tau_{b}\right)\right)^{2}} \mid\right.
$$

Using this information and the geometric model described in detail in Annand (1970), other parameters like flame front area $\left(A_{f f}\right)$ and volume $\left(V_{f}\right)$ can be computed. The latter could be expresed as:

$$
V_{f}=V_{b}+\frac{\mu^{*}}{\rho_{u}}
$$

With all the previous information it is possible to obtain a value for burned mass ratio and heat release to calculate in-cylinder gas thermodynamic properties. After this a new time step appears and the whole process is repeated. Combustion ends when mass fraction burned equals 1 .

\section{COMPUTATIONAL MODEL STRUCTURE}

The model was programmed in Matlab ${ }^{\circledR}$. Model input variables are:

- Fuel: Isooctane and fuel with formula $C_{n} H_{1.7 n}$ (Heywood, 1988) could be use pure or in a blend with ethanol, up to $30 \% \mathrm{v} / \mathrm{v}$ of the latter.

- Atmospheric pressure and temperature.

- Cooling liquid temperature.

- Liquid fuel temperature.

- Residual mass fraction.

- Engine geometry.

- $\quad$ Spark timing in degrees BTDC.

- Compression ratio.

- Fuel-air equivalence ratio.

Table 2) (Mantilla, 2010). The differences between the model and experiments were negligible (below 1E-4\%), for maximum pressure value and
- Crankshaft velocity in rpm.

After reading input variables, the model selects a time step from rpm data to match one (1) degree crankshaft angle. Next, it verifies if valves are closed, if so, closed cycle starts until one of the valves open, when open cycle begins. Output variables are generated for every time step and recorded. After that, a new crank angle is selected and the process starts again.

During closed cycle computation, Equations (18) and (19) were integrated using Simpson's rule (Boas, 1983). When all terms in conservation equations (1) and (2) are determined, they are solved simultanously using Newton-Raphson iteration technique, to predict in-cylinder pressure and temperature for every zone at each time step.

Compression process is finished when piston is at TDC, and expansion begins. Combustion can be computed together with compression or expansion processes.

When crank angle is one step before exhaust valve opening, open cycle start and equations (29) to (32) are solved to obtained thermodynamic properties. Each engine cycle are repeated 3 times to evaluate convergence.

Output variables are:

- In-cylinder pressure and temperature.

- Mean intake velocity.

- Mass fraction burned.

- Heat release.

- Laminar and turbulent flame velocities.

- $\quad$ Flame geometry parameters.

- Burned and unburned zone temperature.

- Burned zone gas concentration.

\section{RESULTS}

Simulations for 34 cases were made for a CFR engine running at $900 \mathrm{rpm}$ (

maximum pressure crank angle. For the area under the pressure curve, Error 3 is presented.

Table 2. Simulations performed. ST values with (*) are MBT.

\begin{tabular}{|c|c|c|c|c|c|c|}
\hline \multirow{2}{*}{ Fuel } & \multirow{2}{*}{ CR } & $\begin{array}{c}\text { ST } \\
\text { [deg. BTDC] }\end{array}$ & $\phi$ & $\begin{array}{c}\text { Atmospheric Pressure } \\
{[\mathbf{P a}]}\end{array}$ & $\mathbf{r p m}$ & $\begin{array}{c}\text { Error 3 } \\
{[\%]}\end{array}$ \\
\hline \multirow{3}{*}{ E0 } & \multirow{3}{*}{7} & $7^{*}$ & 1.00120785 & 100000 & 900 & 0.00793059 \\
\cline { 3 - 8 } & & 10 & 1.00120785 & 100000 & 900 & 0.0346963 \\
\cline { 3 - 8 } & \multirow{2}{*}{7.7} & 15 & 1.00120785 & 99000 & 900 & 1.38742035 \\
\cline { 3 - 8 } & & $7 *$ & 1.00216 & 97000 & 900 & 1.20953075 \\
\cline { 3 - 8 } & & 10 & 1.00216 & 97000 & 900 & 1.04660738 \\
\hline
\end{tabular}




\begin{tabular}{|c|c|c|c|c|c|c|}
\hline Fuel & CR & $\begin{array}{c}\text { ST } \\
\text { [deg. BTDC] }\end{array}$ & $\phi$ & $\begin{array}{c}\text { Atmospheric Pressure } \\
{[\mathrm{Pa}]}\end{array}$ & rpm & $\begin{array}{c}\text { Error } 3 \\
{[\%]}\end{array}$ \\
\hline & & 15 & 1.00216 & 98000 & 900 & 0.39053729 \\
\hline Total E0 & & & & & & 0.54663115 \\
\hline \multirow{16}{*}{ E10 } & \multirow{8}{*}{7} & \multirow[t]{2}{*}{7} & 0.9538 & 98000 & 900 & 1.18671078 \\
\hline & & & 1.00103699 & 99000 & 900 & 0.168028 \\
\hline & & $8^{*}$ & 1.00103699 & 99000 & 900 & 0.17517511 \\
\hline & & 9* & 0.9538 & 99000 & 900 & 1.3587425 \\
\hline & & \multirow[t]{2}{*}{10} & 0.9538 & 99000 & 900 & 0.63524686 \\
\hline & & & 1.00103699 & 99000 & 900 & 0.79216974 \\
\hline & & \multirow[t]{2}{*}{15} & 0.9538 & 98000 & 900 & 0.51162033 \\
\hline & & & 1.00103699 & 99000 & 900 & 0.96740777 \\
\hline & \multirow{8}{*}{7.7} & $5^{*}$ & 0.95755755 & 97000 & 900 & 0.49930926 \\
\hline & & $6^{*}$ & 0.99980274 & 97000 & 900 & 0.24196513 \\
\hline & & \multirow[t]{2}{*}{7} & 0.95755755 & 97000 & 900 & 0.38797073 \\
\hline & & & 0.99980274 & 97000 & 900 & 0.31688814 \\
\hline & & \multirow[t]{2}{*}{10} & 0.95755755 & 98000 & 900 & 1.70508903 \\
\hline & & & 0.99980274 & 97000 & 900 & 1.62267059 \\
\hline & & \multirow[t]{2}{*}{15} & 0.95755755 & 98000 & 900 & 0.7189502 \\
\hline & & & 0.99980274 & 97000 & 900 & 0.3592056 \\
\hline Total E10 & & & & & & 0.34854278 \\
\hline \multirow{15}{*}{ E20 } & \multirow{7}{*}{7} & \multirow[t]{2}{*}{$7 *$} & 0.936 & 97000 & 900 & 0.92521056 \\
\hline & & & 0.99063195 & 99000 & 900 & 0.05177482 \\
\hline & & 9* & 0.936 & 97000 & 900 & 1.71033046 \\
\hline & & \multirow[t]{2}{*}{10} & 0.936 & 97000 & 900 & 1.68796741 \\
\hline & & & 0.99063195 & 99000 & 900 & 0.52362404 \\
\hline & & \multirow[t]{2}{*}{15} & 0.936 & 97000 & 900 & 0.96091002 \\
\hline & & & 0.99063195 & 101000 & 900 & 1.84568375 \\
\hline & \multirow{8}{*}{7.7} & \multirow[t]{2}{*}{7} & 0.93920251 & 96000 & 900 & 0.30778723 \\
\hline & & & 1.00049187 & 97000 & 900 & 0.67682211 \\
\hline & & \multirow[t]{2}{*}{ 8* } & 0.93920251 & 96000 & 900 & 0.25397765 \\
\hline & & & 1.00049187 & 97000 & 900 & 0.11516399 \\
\hline & & \multirow[t]{2}{*}{10} & 0.93920251 & 97000 & 900 & 1.15102812 \\
\hline & & & 1.00049187 & 97000 & 900 & 0.05769144 \\
\hline & & \multirow[t]{2}{*}{15} & 0.93920251 & 98000 & 900 & 1.06057717 \\
\hline & & & 1.00049187 & 98000 & 900 & 0.03206113 \\
\hline Total E20 & & & & & & 0.37225034 \\
\hline \multirow{2}{*}{ E30 } & \multirow{2}{*}{7} & \multirow[t]{2}{*}{7} & 0.889 & 97000 & 900 & 0.17601244 \\
\hline & & & 0.99544319 & 99000 & 900 & 1.27175888 \\
\hline
\end{tabular}




\begin{tabular}{|c|c|c|c|c|c|c|}
\hline Fuel & CR & $\begin{array}{c}\text { ST } \\
\text { [deg. BTDC] }\end{array}$ & $\phi$ & 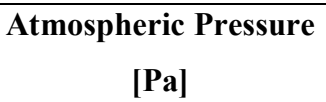 & rpm & $\begin{array}{c}\text { Error } 3 \\
{[\%]}\end{array}$ \\
\hline & & $8 *$ & 1.00103699 & 99000 & 900 & 0.0214461 \\
\hline & & \multirow[t]{2}{*}{10} & 0.889 & 97000 & 900 & 3.98343573 \\
\hline & & & 0.99544319 & 99000 & 900 & 0.28683285 \\
\hline & & $12 *$ & 0.889 & 97000 & 900 & 4.94035795 \\
\hline & & \multirow[t]{2}{*}{15} & 0.889 & 97000 & 900 & 2.91138654 \\
\hline & & & 0.99544319 & 102000 & 900 & 0.19205413 \\
\hline & \multirow{8}{*}{7.7} & \multirow[t]{2}{*}{7} & 0.8895468 & 97000 & 900 & 2.44929372 \\
\hline & & & 0.99205849 & 97000 & 900 & 0.53440079 \\
\hline & & $8 *$ & 0.99205849 & 97000 & 900 & 0.46550269 \\
\hline & & 9* & 0.8895468 & 97000 & 900 & 3.42127115 \\
\hline & & 10 & 0.8895468 & 98000 & 900 & 2.5540325 \\
\hline & & & 0.99205849 & 97000 & 900 & 0.21058575 \\
\hline & & 15 & 0.8895468 & 98000 & 900 & 1.05240871 \\
\hline & & & 0.99205849 & 98000 & 900 & 1.26440594 \\
\hline Total E30 & & & & & & 1.33326829 \\
\hline Total & & & & & & 0.46451227 \\
\hline
\end{tabular}

For graphic validation, the original experimental results (Blizard and Keck, 1974) and four experimental cases (Mantilla, 2010), are compared to the simulated results in Figure 1 to Figure 5. The four cases are:

- Case 1: fuel E0, CR=7, $\phi=1,900 \mathrm{rpm}, \mathrm{ST}=15$, CFR engine.

(Figure 2)

- Case 2: fuel E10, CR=7.7, $\phi=1,900 \mathrm{rpm}$, $\mathrm{ST}=10, \mathrm{CFR}$ engine. (Figure 3)

- Case 3: fuel E20, CR=8.4, $\phi=1,900 \mathrm{rpm}$, $\mathrm{ST}=15, \mathrm{CFR}$ engine (Figure 4)

- Case 4: fuel E30, CR=8.8, $\phi=0.9,900 \mathrm{rpm}$, $\mathrm{ST}=15, \mathrm{CFR}$ engine. (Figure 5)

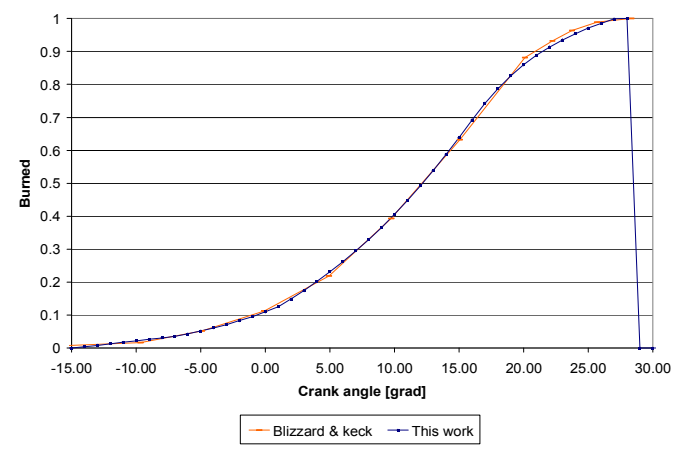

Figure 1. Mass fraction burned comparison between the original and this work. Bore $=63.5 \mathrm{~mm}$, Stroke= $76.2 \mathrm{~mm}, \mathrm{CR}=5,2100 \mathrm{rpm}$.

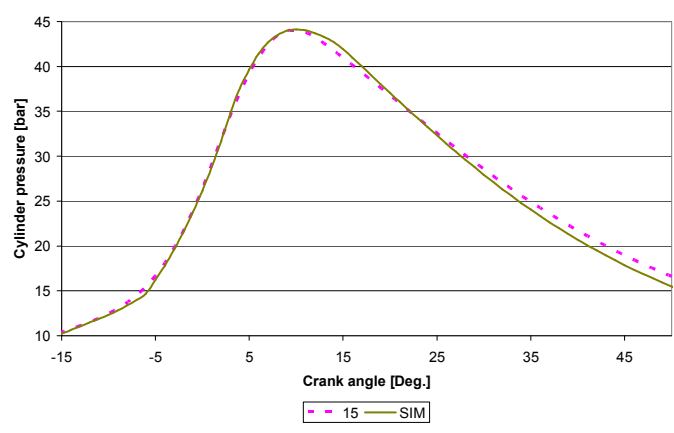

Figure 2. Pressure curve for experimental (15) and simulated (SIM) results. Case 1.

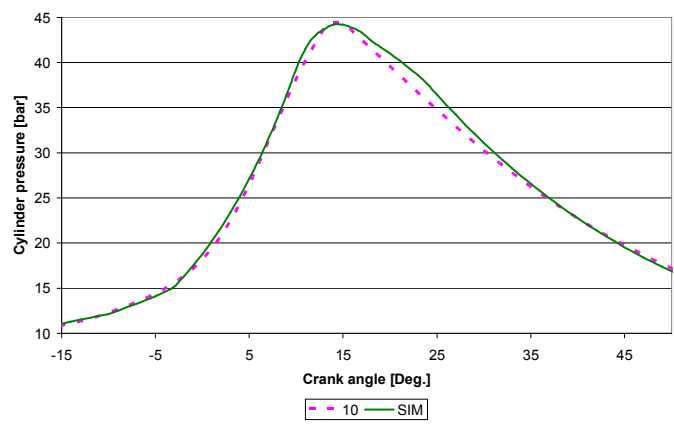

Figure 3. Pressure curve for experimental (10) and simulated (SIM) results. Case 2. 


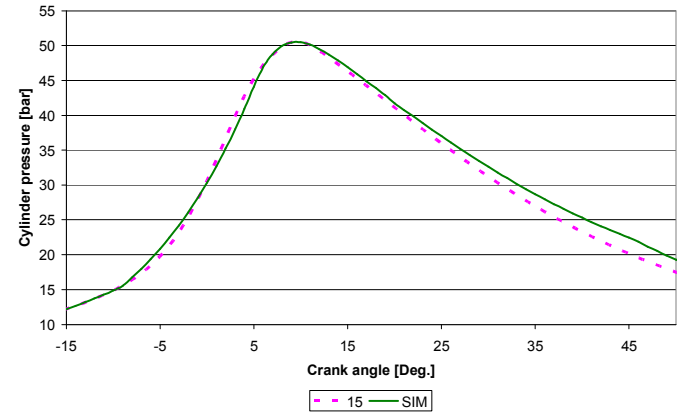

Figure 4. Pressure curve for experimental (15) and simulated (SIM) results. Case 3.

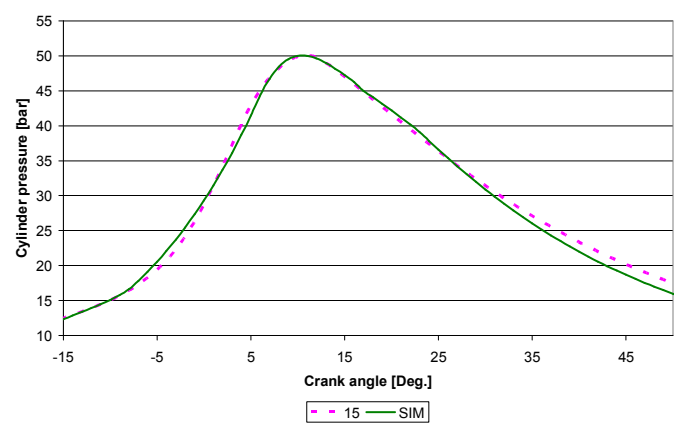

Figure 5. Pressure curve for experimental (15) and simulated (SIM) results. Case 4.

\section{CONCLUSION}

In this paper a phenomenological combustion model is proposed, and simulations on a CFR engine for different compression ratio, spark timing and fuel were performed.

Results show acceptable agree between simulations and experiments, with errors for area under pressure curve less than five percent, and simulation times of one minute top. This means that the model can be used for parametric studies on engines using gasoline-ethanol blends.

The sub-models introduced in equations (13) and (26) proved to be useful when compression ratio, spark timing and fuel change. They worked for all simulated cases without making changes.

\section{ACKNOWLEDGEMENTS}

This study was supported by COLCIENCIAS with project No. 202010013830 contract 472 / 2007.

\section{REFERENCES}

Al-Baghdadi, M. A. S., 2000, Performance Study of a Four-Stroke Spark Ignition Engine Working with Both of Hydrogen and Ethyl Alcohol as Supplementary Fuel, International Journal of Hydrogen Energy, Vol. 25, pp. 1005-1009.
Al-Hasan, M., 2003, Effect of Ethanol-Unleaded Gasoline Blends on Engine Performance and Exhaust Emission, Energy Conversion and Management, Vol. 44, pp. 1547-1561.

Annand, W., and Ha, T., 1963, Heat Transfer in the Cylinders of Reciprocating Internal Combustion Engines, Proc. I. Mech. E., Vol. 17, p. 973.

Annand, W., 1970, Geometry of Spherical Flame Propagation in a Disc-Shaped Combustion Chamber, Journal of Mechanical Engineering Science, Vol. 12, No. 2, pp. 171-182.

Apace Research Ltd., 1998, Intensive Field Trial of Ethanol/Petrol Blend in Vehicles, ERDC Project No.2511, Dungog, NSW, Australia.

Bastianoni, S., and Marchettini, N., 1996, Ethanol Production from Biomass: Analysis of Process Efficiency and Sustainability, Biomass and Bioenergy, Vol. 11, pp. 411-418.

Bayraktar, H., 2005, Experimental and theoretical investigation of using gasoline-ethanol blends in spark-ignition engines, Renewable Energy, Vol. 30, No. 11, pp. 1733-1747.

Beretta, G., Rashidi, M., and Keck, J., 1983, Turbulent Flame Propagation and Combustion in Spark Ignition Engines, Combustion and Flame, Vol 52, pp. 217-245.

Blair, G., 1999, Design and Simulation of FourStroke Internal Combustion Engines, SAE, USA.

Blizard, N, and Keck, J., 1974, Experimental and Theoretical Investigation of Turbulent Burning Model for Internal Combustion Engines, SAE Paper 740191.

Blumberg, P., Lavoie, G., and Tabaczinski, R., 1979, Phenomenological Models for Reciprocating Internal Combustion Engines, Prog. Energy Combust. Sci., Vol. 5, pp. 123-167.

Boas, M., 1983, Mathematical Methods in the Physical Sciences, John Wiley and Sons, second edition.

Durbin, T., Miller, J., Younglove, T., Huai, T., and Cocker, K., Effects of Ethanol and Volatility Parameters on Exhaust Emissions, Final Report CRC Project No. E-67. Coordinate Research Council.

Ferguson, C. R., 1986, Internal Combustion Engines Applied Thermosciences, John Wiley \& Sons.

Gülder, Ö., 1984, Correlations of Laminar Combustion Data for Alternative SI Engine Fuels, SAE Paper No. 841000, pp. 1-23.

Hammel-Smith, C., Fang, J., Powders, M., and Aabakken, J., 2002, Issues Associated with the Use of Higher Ethanol Blends, National Renewable Energy Laboratory.

Hammond, A., 1977, Alcohol: A Brazilian answer to the energy crisis, Science, New series, Vol. 195, No. 4278, pp. 564-566.

Hansen, A. C., Zhang, Q., and Lyne, P. W. L., 2005, Ethanol-Diesel Fuel Blends - a Review, Bioresource Technology, Vol. 96, pp. 277-285. 
Haworth, D., 2005, A Review of Turbulent Combustion Modeling for Multidimensional InCylinder CFD, SAE Paper 2005-01-0993.

Health Canada., 2003, Potential Health Effects of Ethanol-Blend Gasoline, Health Canada Expert Panel Workshop.

Heywood, J., 1988, Internal Combustion Engine Fundamentals, McGrawHill, New York.

Higuera, O., Tristancho, J., and Florez, L., 2007, Biocombustibles y su Aplicación en Colombia. Scientia et Technica, Año XIII, No. 34, Mayo. (in Spanish)

Hsieh, W., Chen, R., Wu, T., Lin, T., 2002, Engine Performance and Pollutant Emission of an SI Engine Using Ethanol-Gasoline Blended Fuels, Atmospheric Environment, Vol. 36, pp. 403-410.

Kojima, M., and Johnson, T., 2005, Potential for Biofuels for Transport in Developing Countries, UNDP/World Bank Energy Sector Management Assistance Programme (ESMAP).

Li, D., Zhen, H., Xingcai, L., Wu-gao, Z., and Jianguang, Y., 2005, Physico-Chemical Properties of Ethanol-Diesel Blend Fuel and its Effect on Performance and Emissions of Diesel Engines, Renewable Energy, Vol. 30, pp. 967-976.

Li, X., Qiao, X., Zhang, L., Fang, J., Huang, Z., and Xia, H., 2005, Combustion and Emission Characteristics of a Two-Stroke Diesel Engine Operating on Alcohol, Renewable Energy, Vol. 20, pp. 1-10.

MacLean, H. L., and Lave, L. B., 2003, Evaluating Automobile Fuel/Propulsion System Technologies, Progress in Energy and Combustion Science, Vol. 29, pp. 1-69.

Mantilla, J., 2010, Combustion Model for Internal Combustion Engines Working with Gasoline-Ethanol Blends. PhD Thesis, Universidad Nacional de Colombia, Medellín, Colombia. (in Spanish)

Mayote, S., Lindhjem, C., Rao, V., and Sklar, M., 1994, Reformulated Gasoline Effects on Exhaust Emissions: Phase 1: Initial Investigation of Oxygenate, Volatility Distillation and Sulfur Effect, SAE technical paper \#941973.

Ministerio de Transporte de Colombia., 2010. http://www.mintransporte.gov.co:8080/inflinea/InfAu tomotores.aspx. Accessed on October 122010.

Morris, D., and Brondum, J., 2000, Does ethanol result in more air pollution? Institute for Local SelfReliance, USA.

Niven, R., 2005, Ethanol in Gasoline: Environmental Impacts and Sustainability Review Article, Renewable and Sustainable Energy Reviews, Vol. 9, pp. 535-555.

Orbital Engine Company, 2002, A Literature Review Based Assessment on the Impacts of a $10 \%$ and 20\% Ethanol Gasoline Fuel Blend on NonAutomotive Engines, Environment Australia.

Schifter, I., Vera, M., Díaz, L., Guzman, E., Ramos, F., and Lopez-Salinas, E., 2001, Environmental Implications on the Oxygenation of Gasoline with
Ethanol in the Metropolitan Area of Mexico City, Environmental Science and Technology, Vol. 35, No. 10, 1893-1901.

Yüksel, F., and Yüksel, B., 2004, The Use of Ethanol-Gasoline Blend as a Fuel in an SI Engine, Renewable Energy, Vol. 29, pp. 1181-1191.

Received: January 16, 2010

Revised: February 14, 2010

Accepted: March 14, 2010 